Published as: Griffiths, M.D. (2013). Eproctophilia in a young adult male: A case study. Archives of Sexual Behavior, 42, 1383-1386.

\title{
Eproctophilia in a Young Adult Male
}

Dr. Mark Griffiths

Psychology Division

School of Social Sciences

Nottingham Trent University

Burton Street

Nottingham

NG1 4BU

United Kingdom

Tel: 0044-115-8482401

mark.griffiths@ntu.ac.uk 
Olfactophilia (also known as osmolagnia, osphresiolagnia, and ozolagnia) is a paraphilia where an individual derives sexual pleasure from smells and odors (Aggrawal, 2009). Given the large body of research on olfaction, it is not surprising that in some cases there should be an association with sexual behavior. As Bieber (1959) noted, smell is a powerful sexual stimulus. Furthermore, the erotic focus is most likely to relate to body odors of a sexual partner, including genital odors. One subtype of olfactophilia is eproctophilia. This is a paraphilia in which people are sexually aroused by flatulence (Aggrawal, 2009). Therefore, eproctophiles are said to spend an abnormal amount of time thinking about farting and flatulence, and have recurring intense sexual urges and fantasies involving farting and flatulence (Griffiths, 2012a). To date, there has been no academic or clinical research into eproctophilia. Therefore, the following account presents a brief case study of an eproctophile and given a pseudonym (Brad). Brad gave full consent for his case to be written up on the understanding that he could not be identified, and that he was guaranteed full anonymity and confidentiality.

Demographic information: Brad, was a 22-year old single man from Illinois. His parents were divorced when he was 6 years old and was an only child. His father remarried when he was 14 years old and he then gained three step-brothers. He has a Bachelor's degree in Fine Arts. He was employed in part-time work, but was looking for another job to help supplement his income. He was engaged in “minimum wage part-time stuff” but would like to get a job in the arts field, but that it required materials that he does not currently have. He believes in "God or a Prime Mover” but does not adhere to any particular religious group.

Brad first approached the author following the publication of an article about eproctophilia on the author's website blog. Brad initially posted a comment in response to 
the article and admitted in the response that he was an eproctophile. In fact, Brad's opening comment was:

"I am an eproctophile...I am not ashamed of my interest. Mind you, I don't tell people what I'm into any more than I discuss any other sexual matter in public.”

Sexual orientation: Brad was asked about his sexual orientation. The response was not straightforward:

"I could be any of three, depending on the perspective. In terms of relationships, I am straight. I could only date or have romantic feelings towards a female. In terms of fetishism, I am bisexual. I get aroused thinking of both males and females in these fetish situations. However, I have no real desire for sexual intercourse, be it penetration or being penetrated, which would make me asexual. (I should probably mention that the arousal mentioned above is a desire to masturbate, not to have sex).”

Background relating to eproctophilia: Brad was asked about his first experience(s) of eproctophilia. He claimed that compared to other eproctophiles who had “colorful first experiences,” that his experience was “a bit more tame than most, which is disappointing in a way.” Brad recalled that in middle school he had a crush on a particular girl. He thought "she was the most beautiful thing [he] had ever seen." She was very athletic, ran 10 miles every day, was fit and toned, and was also sweet, shy, and very attractive (“cute”). When talking with his friends, Brad recalled that one of them mentioned that the girl he had a crush on had farted in her science class. As Brad said: “This blew my mind. Prior to that, I'd never really considered it. I knew by simple biology that girls farted, but hearing that the girl I had been fawning over was capable of such a thing sparked a strange interest in me.”

Brad first engaged in an eproctophile act at around the age of 16 or 17 years of age. He was with a male friend and up to that point he had considered himself as heterosexual. This was until he heard his male friend fart in front of him. Brad recalled:

"It was rather appealing in sound, and I found myself fixating on it. At first, I didn't want to admit I was into his farting, but eventually I decided to experiment. I set up a bet at some point and intentionally lost, with the wager being the right to fart in the loser's face 
for a week. I continued to lose such bets once every few weeks for about two years.”

Eproctophilia experiences: Brad was asked about his thoughts surrounding eproctophilia.

He claims to "enjoy everything about it” and had experienced it directly.

"I'm not sure how graphic of details you would like, but I have had my face farted on by both men and women, at point blank range. I like the sound and the smell. The 'worse,' the better. In terms of sound, I prefer a deep bubbling sound. In terms of smell, I like acrid sulfur. I prefer the farter to be clothed. I don't particularly like seeing the anus open. It's not revolting to me, I just prefer fabric for three reasons. Firstly, the sound tends to be better with fabric, particularly jeans or nylons. Second, the smell lingers in cloth, whereas in the nude it is a relatively quick blast of smell. Third, I like the look of butt cheeks better when they are defined by fabric."

Brad was specifically asked why he preferred sulfurous farts. He said that they "tended to be the strongest and most disgusting.” In fact, Brad said that:

"The more disgusting, the more I like it as it heightens the sense of duality. The more disgusting the fart and the prettier the lady, the more of a schism it is between the societal expectation and the reality. As for men, it's simply more dominating for it to be a really gross fart than a mild poot."

Brad was also asked how he met other like-minded people that shared his eproctophilic interests. He said that there were several online forums that cater for interests related to eproctophilia. Although he was happy to engage in online communication with other eproctophiles, he had no desire to meet them in person. In order to engage in eproctophilic acts, Brad said that he would explain his fetish to his significant other and hope they would be willing to do it for him (i.e., fart in his face). Brad was also asked if there was any difference between men and women farting in his face, and whether male farting aroused him in the same way as female farting. He responded: "More or less, yes. It's slightly different, as it's a slightly different mindset. It's more about domination with males, as they don't have the "dainty" expectation to break."

Brad was asked whether he was more sexually aroused when engaged in eproctophile sexual activity than when engaged in "normal" sex. He then said that he may 
be "technically asexual” as he had no desire for actual sex (as he preferred masturbation to sexual intercourse). He was also questioned about the extent to which the eproctiphile acts were masochistic. He responded:

"Sometimes. One of my more common fantasies is receiving a fart as a reward for completing a task. I play video games, for instance, and one includes me helping a girlfriend solve a puzzle in a game. Then, while still playing, she tells me to get ready for my reward and lets one rip. There's an idea of subservience, not necessarily masochism. An idea of being there without being the focal point, where she lets me smell her farts and rub her feet and cuddle up and such, without fussing too much over me. I enjoy all aspects, really, from the $\mathrm{S} / \mathrm{M}$ standpoint in which someone dominates me by farting on me, to the subservient aspect of being like a pet or article of furniture in which she isn't particularly dominating, just coexisting, to the aspect of dominance for myself in which I learn her closely guarded secret of what her farts sound and smell like.”

Brad was asked whether he got any sexual pleasure from farting on other people or was it only the act of receiving. He said he preferred receiving, but would not be opposed to giving should he have a partner who wanted it. He said he did not have any real desire to do so, but it would sexually arouse him to know they liked it. In this instance, Brad said it would be more that he was pleasing his partner than how he was pleasing them. One of the more interesting things that came from interviewing Brad was that he was very forthright on what he believed about eproctophilia and other people's perceptions of it. He said:

"Allow me to shed some light on why farting, of all things, is sexually interesting to us. First, let me mention that we are not sexually attracted to flatulence, per se. We are attracted to the person RELEASING the flatulence. Unattractive people farting, to us, is like seeing unattractive people having sex for you."

He went on to say the eproctophiles are aroused by the idea of dominance, and that by being farted on, they are being put "in their place, much with any sort of S/M type of fetish.” He was particularly interested in the concept and idea of duality:

"For others, myself included, it is a matter of dualities. Social norm dictates that people in general, particularly females, do not fart in public, for others to hear. To see a beautiful, delicate lady passing wind is a breach of those expectations in a profound manner. That a beautiful woman is capable of producing a "disgusting" sound and smell is what attracts us, and makes us want to experience it. It can also be a matter of humanization. Again, social ideologies tend to place the beautiful, particularly women, on a pedestal of what makes a 
conceptual or archetypal woman. To hear her pass wind is to hear an admission of humanity, that she is the same as the rest of us. It is to learn her dark secret, the sounds and smells of her uncontrollable biological functions. This is more of a dominant matter, as it is more about wrenching her humanity into focus while society attempts to hide it. Therefore, it is not always a matter of female dominance. However, due to the internet pornography market, most producers choose to follow the dominatrix stereotype, as it is a reliable source of income and a familiar sexy medium.”

Brad was asked if he experienced any sexual pleasure from watching eproctophilia videos (such as those on YouTube). Given that smell is such an important part, I was interested to know whether "second-hand" sources were less arousing. Brad responded that he did get sexual pleasure from watching such films. In fact, he added:

"While smell and the tactile sense of face sitting are important, sound is also another key factor. Being able to see that girls DO fart, or sort of live the fantasy out vicariously, is what I have to do. I suppose vanilla porn could be a good analogy. The physical sensation of sex is obviously very important. People still get aroused watching porn even though they can't feel it, and I think it's exactly the same with myself. When watching pornography, it's more about the thought of it."

Other sexual interests and fetishes: Brad was also asked if he had another sexual interests and said there were three other specific things he liked that turned him on sexually. Although he said that he was "not a fan of scat", the first one appeared to related to coprophilia as he reported that:

"I am into seeing attractive people (mostly females) pooping their pants. It has obvious relations to the matter at hand."

Secondly, he said although it was not fetishistic in any way, he loved giving foot rubs to people who he was in a relationship with. He claimed that this behavior did not really sexually arouse him but that he simply liked female feet in a "platonic" way. He described female feet as "cute" and that he had strong desires to massage them. Finally, Brad claimed he had "one fetish since birth" and went on to explain further:

"It is one I am not proud of, but it exists and may help your study. I have a crush fetish, which is essentially arousal from seeing people step on objects or insects. This particular one has had a lot of bad publicity. As for this one, I can't tell you where it originated. I 
remember rubbing myself in my crib as a baby to such thoughts, leading me to believe I may have literally been born with it. I could have been no older than $2 \frac{1}{2} 2$ years old. Keep in mind, these are very primal memories which are mostly a blur. All I recall is that around the time of those memories, I would also rub myself to the thought of someone stepping on an insect, or sometimes a machine made to crush up children like myself. Come to think of it, that last one may have been caused by seeing an apple cider press as a toddler. I also seem to recall that, and being afraid of it because of how it "hurt" the apples."

Brad was also asked if he thought there was any connection between his crush fetish and eproctophilia. He responded that if there was any connection, it concerned "the idea of the duality," i.e., he would not expect to see a woman fart in front of him and similarly, he would not expect a woman to kill an insect in front of him for no real reason. In relation to his crush fetish, he also reported:

"It's my oldest fetish with no known origin, and I like it for about the same reason as eproctophilia. Maybe that I also disliked seeing people kill bugs as a kid, while also finding it arousing. I was quite the pacifist. Also, when I first discovered ejaculation, I made the connection that ejaculating was somewhat like when a bug is stepped on. I thought about a bug squirting under pressure and then I would do the same. May or may not be relevant, but it was a connection I made as a kid.”

Discussion: The prevalence and incidence of eproctophilia is assumed to be negligible given that no previous case studies have ever been published. However, other eproctophiles in addition to this case clearly exist as the topic is discussed by selfconfessed eproctophiles in various online discussion groups (Griffiths, 2012a). Brad’s account of his early eproctophile experiences are suggestive of behavioral conditioning and/or sexual imprinting - in this case classical conditioning where being sexually aroused by an attractive women is paired with something that is not inherently sexual (in this case, flatulence) and then starts to become an erotic focus in and of itself (Akins, 2004). From an evolutionary perspective, 'disgust' has been argued to be a psychological system for protecting humans from infection through disease avoidance behavior (Curtis, de Barra \& Aunger, 2011). Most people probably view flatulence as a disgusting behavior yet eproctophiles do not. This seems to support research that suggests disgust (is in part) 
socially learned (Haidt, McCauley \& Rozin, 1994).

In DSM-5, the definition of a paraphilia will be: “any intense and persistent sexual interest other than sexual interest in genital stimulation or preparatory fondling with phenotypically normal, physically mature, consenting human partners...There are also specific paraphilias that are generally better described as preferential sexual interests than as intense sexual interests.” Brad's description of his sexual preference for flatulent individuals along with the seemingly intense sexual urges, fantasies, and behaviors are at least suggestive of a genuine paraphilia. However, although the behavior may have been cognitively salient, it was not behaviorally salient as the number of partners willing to engage in the activity was very limited. Furthermore, Brad had very specific criteria for the behavior to be sexually arousing (i.e., the person had to fart while fully clothed as it sounded better, and the smell was longer-lasting, and the farts had to be acrid smelling). However, there was little evidence that these were recurrent and insistent. Stoller (1975) asserted that paraphilias originate from childhood traumatic experiences during that are subsequently relived and overcome by reaching sexual climax. However, the onset of this particular paraphilia was not associated with any traumatic incident and as mentioned above.

Cantor, Blanchard, and Barbaree (2009) have noted that paraphilias are often comorbid. In this particular case, eproctophilia was part of a wider set of fetishistic and/or paraphilic behavior including crush fetish and (voyeuristic) coprophilia. While there is some literature on coprophilia (e.g., Hingsburger, 1989; Sandnabba, Santtila, Nordling, Beetz \& Alison, 2002), there has been very little published from an academic and/or clinical perspective on crush fetishes. Brad himself sees clear similarities between his interest in eproctophilia and being sexually aroused by watching females defecate (as he specifically noted that watching defecating females has "obvious relations to the matter in 
hand”, i.e., eproctophilia). The co-occurrence of Brad's eproctophilia with traits of sexual masochism - such as the deliberate losing of a bet so that resulted in Brad being farted upon all week by his male friend - demonstrates that the behavior has other paraphilic elements. A number of times, Brad mentioned the sadomasochistic elements of the eproctophilic behavior.

According to Terry and Vasey (2011), the scientific value of case studies includes both their utility in highlighting rare phenomena and their role in the generation of new research questions and hypotheses. The eproctophile case presented in this article hopefully fulfils these values. Clearly, this is just one case study and Brad is unlikely to be representative of the entire eproctophile community. Other developmental routes into eproctophilia may be possible. Further research is needed to assess the extent to which this case study is representative of eproctophiles more generally, and whether the etiological and developmental pathways are more complex than that described in this instance. This particular case also highlights the need for further research into crush fetishism as there are no empirical data on this type of fetish (Griffiths, 2012b).

Finally, the article also highlights the importance of the internet in recruitment of people with sexually paraphilic and/or fetishistic behavior for academic study. Over the last decade, there have been a number of studies that have reported paraphilic behavior by using online methodologies such as studies into zoophilia, feederism, hypoxyphilia, and sexsomnia (Griffiths, 2012c). Without the internet, it is unlikely that present case study would have come to light. The person would not have been able to contact the researcher and the researcher would not have been able to carry out the interview online. The online medium appears to be a particularly good medium for collecting data on unusual sexual paraphilias and fetishes as online data collection is much better for collecting sensitive compared to offline methods (Griffiths, 2012c). 


\section{REFERENCES}

Aggrawal A. (2009). Forensic and medico-legal aspects of sexual crimes and unusual sexual practices. Boca Raton, FL: CRC Press.

Akins, C. K. (2004). The role of Pavlovian conditioning in sexual behavior: A comparative analysis of human and nonhuman animals. International Journal of Comparative Psychology, 17, 241-262.

Bieber, I. (1959). Olfaction in sexual development and adult sexual organization. American Journal of Psychotherapy, 13, 851-859.

Cantor, J. M., Blanchard, R., \& Barbaree, H.E. (2009). Sexual disorders. In P. Blaney \& T. Millon (Eds.), Oxford textbook of psychopathology (2nd ed., pp. 527-548). New York: Oxford University Press.

Curtis, V., de Barra, M., \& Aunger, R. (2011). Disgust as an adaptive system for disease avoidance behaviour. Philosphical Transactions of the Royal Society B, 366, 389-401.

Griffiths, M. D. (2012a). Farting company: The strange world of eproctophilia. Retrieved from: http://drmarkgriffiths.wordpress.com/2012/05/11/farting-company-thestrange-world-of-eproctophilia/

Griffiths, M. D. (2012b). Trample leaning: A beginner's guide to crush fetishism. 
Retrieved from: http://drmarkgriffiths.wordpress.com/2012/05/17/trample-leaning-abeginners-guide-to-crush-fetishism/

Griffiths, M. D. (2012c). The use of online methodologies in studying paraphilia: A review. Journal of Behavioral Addictions, 1, 143-150.

Haidt, J., McCauley, C., \& Rozin, P. (1994). Individual differences in sensitivity to disgust: A scale sampling seven domains of disgust elicitors. Personality and Individual Differences, 16, 701-713.

Hingsburger, D. (1989). Motives for coprophilia: Working with individuals who had been institutionalized with developmental handicaps. Journal of Sex Research, 26, 139140.

Sandnabba, N. K. Santtila, P., Nordling, N. Beetz, A. M., Alison, L. (2002). Characteristics of a sample of sadomasochistically-oriented males with recent experience of sexual contact with animals. Deviant Behavior, 23, 511-529.

Stoller, R. J. (1975). Perversion: The erotic form of hatred. New York: Pantheon Books.

Terry, L. L. \& Vasey, P. L. (2011). Feederism in a woman. Archives of Sexual Behavior, 40, 639-645. 